\title{
Effect of Local Shunting on the Electrical Mismatch Losses in Industrial Silicon Photovoltaic Modules
}

\author{
Somasundaran Pannientakandi ${ }^{*}$, Rajesh Gupta ${ }^{1}$ and Shilpi Manjoli² \\ ${ }^{1}$ Department of Energy Science and Engineering, Indian Institute of Technology Bombay, Mumbai, India \\ ${ }^{2}$ Department of Electronics and Communication Engineering, Government Engineering College, Kozhikode, India \\ Email: somasundarankerala@gmail.com
}

\begin{abstract}
The paper presents the results of investigation on the influence of an ohmic shunt located at various spatial positions on the photovoltaic module performance by distributed diode model based simulations. By systematically varying the parameters such as the resistance of the shunt, proximity to the finger and busbar metallization, area of the shunt, irradiance and number of shunted cells in the module, a deep insight about the impact of the shunt on the module electrical performance have been obtained. Further, influence of spatial location of shunts has been studied by assuming a shunted region of same area and severity at different positions in the photovoltaic module, based on the proposed simulation approach. The study revealed novel insights about significance of spatial locations of shunts and the proximity of finger and busbar metallization. In general, it was found that the proximity to the busbar and finger metallization and the shunt position holds the key to the impact the shunt will have on the photovoltaic module performance in addition to the resistance of shunt itself. Quantum of loss due to the presence of finger or busbar metallization in close proximity of shunt location has been revealed by the proposed approach. This understanding can enable to gain an improved performance of the photovoltaic cell and module, by implementing the approach at the cell production level.
\end{abstract}

Keywords: PV module characterization, shunts, electrical mismatch loss, performance degradation.

\section{Introduction}

Shunts present in various locations of a single solar cell or several solar cells within a photovoltaic module can be detrimental to its performance and reliability [1 - 9]. Further, it is well known that the reliability and performance of photovoltaic modules can be limited by thermal issues occurring in regions with high localized self-heating or hot spots created by the shunts, which are often observed to induce a strong degradation of the photovoltaic cells and of the module itself leading to a drastic reduction of the module life time and even to hazardous operating conditions [4]. These reliability issues due to shunts can be aggravated when a PV cell operates in reverse bias condition, which might take place when one PV cell in a module is shaded and others are still generating current [4]. In such a situation, it has been found that $[10,11]$, a significant reverse current can flow through the shaded cell and this can lead to a premature break down and permanent degradation, because the current is observed to flow through the shunt resistance. It would be interesting to understand the possible improvement in the photovoltaic module performance, with either removal of shunts $[12,13]$ or their isolation $[14,3,15]$ or preventing them from occurring at least in the most detrimental locations during cell production. The aim of the present work is to present a systematic study of influence of ohmic shunts at significant spatial locations in an industrial Silicon photovoltaic module. Distributed diode model, [16 - 23], developed based on experimentally measured parameters, has been utilized for the study. Ohmic shunts have been simulated at various critical spatial locations in the photovoltaic module.

A comprehensive understanding of the influence of the critical shunt locations in the industrial Silicon photovoltaic module can be useful to achieve a dramatic improvement in the electrical performance of the PV module by preventing the occurrence of shunts at the identified critical locations or by detecting and isolating the shunts at the identified critical locations or by removing them and replacing with shunt-free area during in-line production. The localised shunts can be imaged and detected using an IR camera $[3,15]$ or liquid crystal sheets [15]. Lock-in Infrared Thermography can be used for the imaging 
and detection of strong shunts in a few seconds of measurement time [18]. Based on the criticality, the localised shunts can then be isolated by a combination of laser scribing and chemical etching as proposed in [15] gaining an improved performance of the PV module. Further, severe shunts under busbar or finger metallization in multi/mono-crystalline solar cells to be connected within a module can be repaired in an effective manner by the chemical etching method proposed in [3].

Though it is well known that the shunts cause electrical mismatch losses in the PV module, because the shunts basically influence the I-V characteristics of the PV cells, the quantum of the electrical mismatch losses as a result of the existence of ohmic shunts at different spatial locations in the PV cells connected in a PV module has not been investigated comprehensively till now. In the present work, an approach has been proposed to investigate the mismatch losses due to the existence of ohmic shunts at critical spatial positions in a typical industrial Silicon photovoltaic module.

\section{Approach and Methodology}

In order to model and analyze the performance of PV module in the presence of shunts and to study the losses induced by these shunts in a typical industrial Silicon PV module, a distributed diode model of PV module has been developed from the electrical equivalent circuit of illuminated solar cell, consisting of a single diode in parallel with a current source and a shunt resistance, with a series resistance. An electrical circuit simulator PSpice [24] has been used to simulate this developed model. Main parameters for this simulation have been obtained experimentally from the experimental dark I-V characteristics of solar cells. Ohmic shunts of same area and same absolute shunt resistance have been simulated at various significant spatial positions in the PV cells interconnected in the PV module. Considering the fact that, normally the modules are series connected and to simplify the approach, only the series connection of the PV module has been considered in the present work.

Degradation in output power and open circuit voltage have been measured in terms of relative power and relative open circuit voltage which were calculated with respect to the values when the photovoltaic module is not shunted. Important effect of irradiance on shunt related losses has been accounted for by performing simulations at different irradiance levels. The study has provided further insight into the shunting phenomena.

The influence of shunt on the relative power of the photovoltaic module at each spatial position has been found by comparing the power at MPP for the following two distinct cases: 1) when the shunt is present in the photovoltaic module and 2) when the shunt is not present in the photovoltaic module (i.e., after replacing the shunted area by the shunt-free area). The influence of shunt on the relative open circuit voltage has been found in a similar manner.

Effect of shunt magnitude, number of shunted cells, proximity of metallization fingers and busbars, area of the shunt and irradiance have been systematically investigated utilizing the developed distributed diode model of the photovoltaic module. Some parameters (shunt resistance, reverse saturation current, ideality factor, sheet resistivity etc.,) which were required for the distributed diode model have been obtained experimentally in order to simulate the I-V characteristic of shunt-free solar cell. The simulated and experimental dark I-V characteristic of the shunt-free solar cell has been compared to support the model and simulation. Based on this model and simulation, shunt losses in quantitative terms have been estimated.

Critical influence of irradiance on the losses due to shunts has been taken into account by varying irradiance from $1 \mathrm{~W} / \mathrm{sq}$. m. to $1000 \mathrm{~W} / \mathrm{sq}$. m. in a series of logical steps. The investigation has contributed deeper insight into the effect of irradiance on shunting.

There are many parameters which can have spatial inhomogeneities like defects in material, intensity of illumination etc., in a PV module having a large area. Distributed diode model provides flexibility in handling the inhomogeneities in several parameters and predicting the electrical performance of the PV module. Different effects could be investigated and their impact on the electrical performance of the module could be studied.

Presented distributed diode model has been utilized to determine the shunt currents in the shunted and shunt-free areas of the shunted solar cells connected in the PV module. Each PV cell in the PV module is divided into smaller elementary regions in the distributed diode model, and the model has 
been exploited to determine electrical mismatch losses by finding the currents flowing in shunted regions for different conditions of shunting at the considered significant shunt locations.

A deep knowledge of the effect of the significant shunt positions in the industrial Silicon PV module can be useful to realize an impressive improvement in the overall performance of the industrial Silicon PV modules through prevention of creation of shunts at the identified significant spatial locations.

The basic methodology for implementing the proposed approach for simulation by PSpice is illustrated in Fig.1. Shunting can happen in very small regions in the photovoltaic cell, and therefore it is necessary to divide the given PV cell area into a large number of elementary areas, in order to represent each small region of the solar cell in the model. All industrial silicon cells within the PV module considered in the present work have an area of $62 \mathrm{~mm}$ x $37 \mathrm{~mm}$. For developing the model, the solar cell was divided into 1421 elementary areas in order to accommodate finger size of solar cells.

Each elementary area has been modeled by solar cell equivalent circuit consisting of a diode, a shunt resistance and a current source in parallel as shown in Fig. 2. Resistances were connected between neighboring elementary areas taking into account the emitter sheet resistance of the cell. The base resistance of cell has been neglected since its value is very small compared to the sheet resistance of top $\mathrm{n}$ layer. Fingers and bus bars of the cell have been modeled after measuring the respective resistances.

\section{Model}

In the distributed diode model, which is illustrated in Fig. 2, each PV cell has been divided into smaller elementary areas, and each elementary area has been modelled by Shockley's one diode model [25]. These elementary areas are considered to be homogeneous and are substituted by lumped one diode model circuits. The elementary area circuits have been interconnected to create the complete model of the PV cell. Every PV cell in the simulated PV module is connected in series, and the cells have been interconnected with bus bar resistors. By the aforementioned approach, the homogeneity can be confined to small areas and the influence of each individual area on the PV module's electrical performance can be investigated.

For simulation of a PV cell and PV module utilizing the proposed distributed diode model, the area of each PV cell has been divided into 1421 elementary areas. The parameters of each elementary area have been determined according to the dimensions of the elementary area in the distributed diode model. The simulation parameters have been summarized in Table 1.

Table 1. Simulation parameters [25].

\begin{tabular}{lc}
\hline Parameters & Value \\
\hline Number of busbars & 1 \\
Number of fingers & 14 \\
Cell length & $6.2 \mathrm{~cm}$ \\
Cell breadth & $3.7 \mathrm{~cm}$ \\
Number of elementary areas & 1421 \\
Number of rows & 29 \\
Number of columns & 49 \\
Photo-generated current & $4.72 \mathrm{E}-04 \mathrm{~A}$ \\
Reverse saturation current & $7.83 \mathrm{E}-10 \mathrm{~A}$ \\
Ideality factor & 1.7 \\
Shunt resistance (shunt-free area) & $7.815 \mathrm{E} 05 \Omega / \mathrm{sq}$. \\
Sheet resistance & $40 \Omega / \mathrm{sq}$. \\
\hline
\end{tabular}




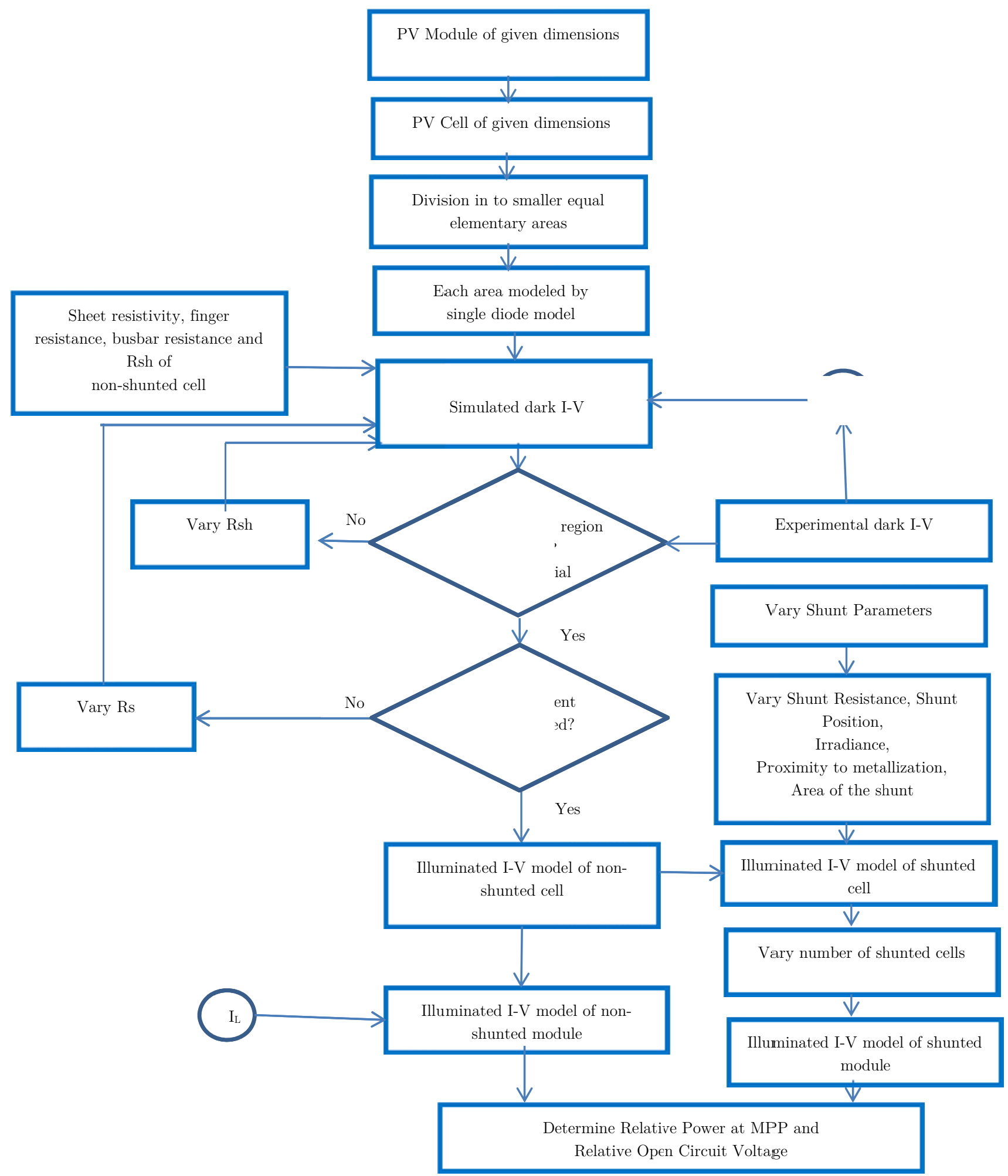

Figure 1. Flowchart describing the methodology adopted for implementing the proposed simulation approach. 


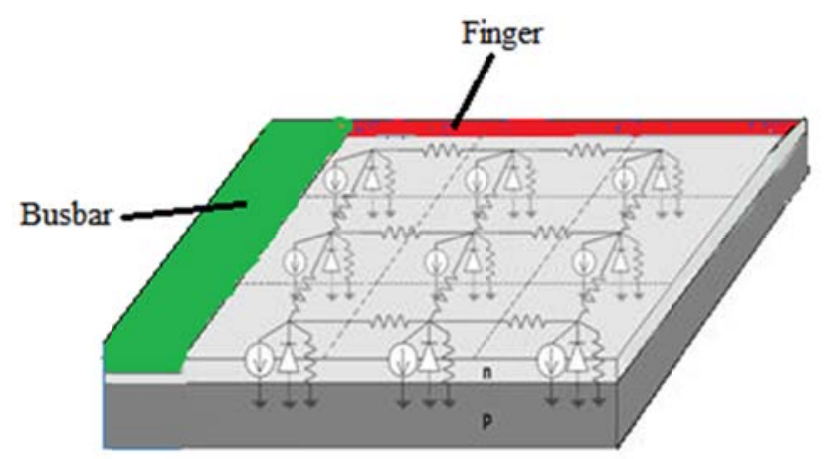

Figure 2. Distributed diode model of the photovoltaic cell showing $3 \times 3$ elementary areas and wherein each elementary area has been modelled by the Shockley's one diode model [25].

Current flow in the model can be described based on the Shockley's diode equation:

$$
I=I_{L}-\frac{V+I R_{s}}{R_{s h}}-I_{o}\left[\exp \left\{\left(\frac{q}{n k T}\right)\left(V+I R_{s}\right)\right\}-1\right.
$$

where $\mathrm{I}_{\mathrm{L}}$ is the photo-generated current $(\mathrm{A})$

$\mathrm{I}$, the net current flowing through the cell (A),

$\mathrm{I}_{0}$, reverse saturation current $(\mathrm{A})$,

q, electronic charge $(\mathrm{C})$,

$\mathrm{V}$, applied voltage across terminals of the cell (V),

n, ideality factor,

$\mathrm{k}$, Boltzmann's constant $(\mathrm{J} / \mathrm{K})$,

$\mathrm{T}$, absolute temperature $(\mathrm{K})$.

$\mathrm{R}_{\mathrm{s}}$ is the series resistance $(\Omega)$,

$\mathrm{R}_{\text {sh }}$ is the shunt resistance $(\Omega)$.

In the dark condition, the equation reduces to the following form:

$$
I=I_{O}\left[\exp \left(\frac{q V}{n k T}\right)-1\right]
$$

From experimental dark I-V of the cell, two parameters, reverse saturation current $\left(I_{0}\right)$ and the ideality factor $(n)$ are determined by plotting $\ln (I)-V$ graph. The forward dark I-V characteristic of a solar cell can be written in following form:

$$
\operatorname{In}(I)=\operatorname{In}\left(I_{o}\right)+q V / \mathrm{nkT}
$$

The parameters $I_{\mathrm{o}}$ and $n$ were thus calculated from the intercept and slope of the curve by using equation (3). Diodes were characterized with these respective $I_{0}$ and $n$.

For obtaining the simulated dark I-V characteristics, varying voltage was applied across the $\mathrm{p}$ and $\mathrm{n}$ side. In case of illuminated I-V curve, current source corresponding to the short circuit current of elementary diode was applied.

In a photovoltaic cell, at very low voltages under the forward bias conditions, a very minimum current flow through the PV cell which is predominantly determined by the shunt resistance $\left(\mathrm{R}_{\mathrm{sh}}\right)[26]$ of the PV cell. Shunt resistance $\left(\mathrm{R}_{\text {sh }}\right)$ of the cell has been experimentally measured at very low voltage from the slope of experimental dark I-V curve. This measurement was performed on a number of shuntfree cells after verification by LIT measurements. Shunt-free cell has been chosen from the same batch, from where the shunted cells have been chosen for this entire study.

For a shunt-free cell, shunt resistance of each elementary area has been estimated by considering the uniform distribution of overall shunt resistance over the cell. The same elementary shunt resistance value has been used in shunt-free region of the shunted cell during simulation.

The model has been verified with several shunt-free and shunted industrial multi-crystalline and mono-crystalline Silicon solar cells. An illustration of model verification can be seen in Figure 3, which compares the experimental dark I-V curve obtained by the Solar Simulator in the laboratory and the simulated dark I-V curve obtained from the distributed diode model of a typical shunt-free multi- 
crystalline solar cell. There is a good degree of agreement between both the curves, which supports the validity of the developed model.

\section{Results}

The intensity of solar radiation incident on the different PV cells connected in the module will decide primarily the quantity of electricity generated in each PV cell. Hence the intensity of incident solar radiation emerges as one of the significant parameters to be considered in the mismatch situation. However, the present investigation assumes that all PV cells in the module are uniformly illuminated.

\subsection{Comparison of Performance of Shunted Cell in the Module and Shunt-Free Cell}

The most important parameter determining the quantum of the influence due to shunting is the magnitude of the shunt or in simple terms, the value of the shunt resistance offered by the PV cell. The value of the shunt resistance offered by the PV cell is in turn determined by the shunt resistance offered by the shunted region of the PV cell and area of the shunted region. To have a realistic picture of the severity of shunting and the resulting mismatch, a shunt resistance of $1 \mathrm{Ohm}$ has been chosen for the shunted area, whose value has been selected based on the published literature [27].

From the Lock-in Infrared Thermography (LIT) images, it has been observed that the busbar shunt is normally occurring in many of the cells connected in the module. The busbar shunt has been modelled by assuming a shunt area of 1 node, whereas the total cell area has been represented by 1421 nodes as shown in Table 1. An overall shunt resistance of $1 \mathrm{Ohm}$ has been simulated and the area of the simulated shunted region is $0.0625 \mathrm{sq}$. $\mathrm{mm}$. The severity of the shunting due to this shunted region can be understood from the graph shown in Fig. 4, which compares the power curve of the shunted cell and the shunt-free cell connected within the PV module. The power curve has been plotted with respect to the module voltage instead of the corresponding cell voltages for the purpose of comparison.

It can been seen that the power curve of the shunted cell goes even into the third quadrant and the output power becomes negative for some voltage range, in the low voltage region of the curve, which implies effectively that the shunted cell has become a power dissipater rather than a power generator. The power generated by the shunted cell and the shunt-free cell, in each situation, has been determined from the cell current and the corresponding cell voltage.

Due to the electrical mismatch, the shunted cell has been driven into the reverse bias condition by the remaining cells within the PV module, which are non-shunted and operating at a forward voltage, for module voltage ranging from $0 \mathrm{~V}$ (corresponding to the short circuit condition) up to $2 \mathrm{~V}$. The above finding implies that, if the module operating point shifts to the region corresponding to the aforementioned voltage range, the influence of electrical mismatch can affect the module's performance more critically. For the particular case of PV module illustrated in the Fig. 4, the shunted cell has been dissipating a power of $0.107 \mathrm{~mW}$ at near short circuit or no load conditions.

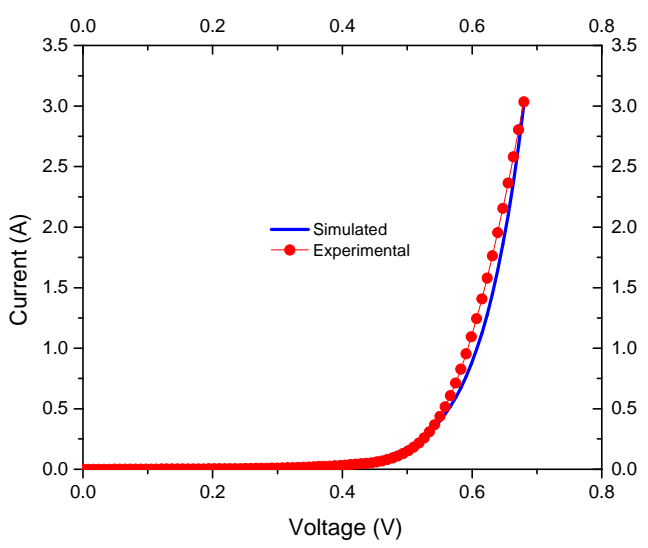

Figure 3. Comparison of experimental and simulated dark I-V curves for a typical shunt-free multi-crystalline solar cell $[21]$. 


\subsection{Influence of Shunt Magnitude}

Degradation in output power and open circuit voltage have been determined in terms of relative power and relative open circuit voltage which have been determined with respect to the values of output power and open circuit voltage if the photovoltaic module is not shunted. The effect of shunt on the relative power at each spatial location of shunt has been determined by comparing the output power at MPP for the following two distinct situations: 1) if the shunt exists in the PV module and 2) if the shunt does not exist in the PV module (i.e., by removing and then replacing the shunted region by the shunt-free region).

Figure 5 illustrates the variation of relative power with shunt resistance considering three different positions of shunts. Figure 6 presents the variation of relative open circuit voltage for three local spatial positions of shunts in the PV module considered in the present work. A comparison of Fig. 5 and Fig. 6 reveals that, in comparison to the relative power, the influence on relative open circuit voltage is comparatively lesser, which is in agreement with the findings in [27] for the thin film module.

\subsection{Influence of Irradiance}

It has been understood from the present investigation that the shunt related losses are critically dependent upon the magnitude of the shunt resistance and local position of the shunt as well as the proximity of shunt to the metallization. However since the photovoltaic generation in a PV cell depends primarily on the illumination intensity, it is expected that the current drawn by the shunt will depend critically on the solar radiation incident on the PV module as well as the resistance offered by the shunt. Therefore it would be of great interest to study how the criticality of losses due to shunts will be affected by the variation in irradiance levels for various shunt locations.

Output power and open circuit voltage has been determined for different incident solar irradiation intensities and compared with the output power and open circuit voltage for the PV cell having no shunts. For the purpose of comparison, a relative output power ([Output power of the shunted photovoltaic module / Output power of the shunt-free photovoltaic module at the same irradiance]) and a relative open circuit voltage ([Open circuit voltage of the shunted photovoltaic module / Open circuit voltage of the shunt-free photovoltaic module at the same irradiance]) have been defined.

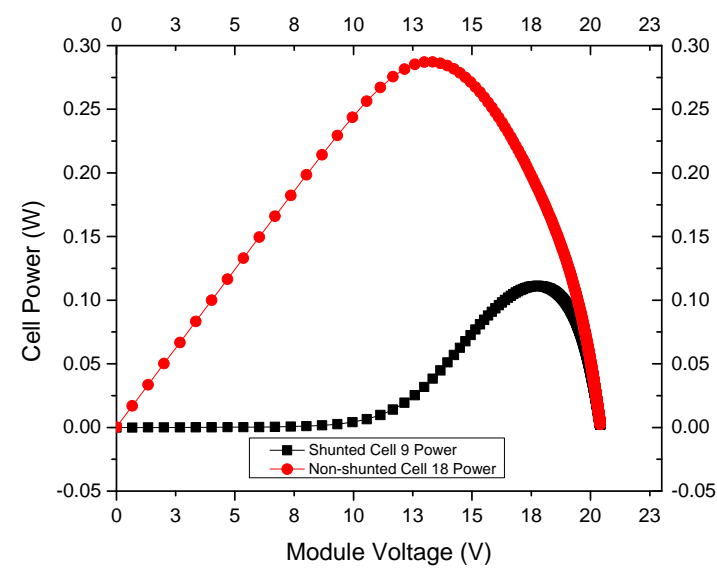

Figure 4. Variation of shunted and non-shunted cell power with respect to the module voltage. 


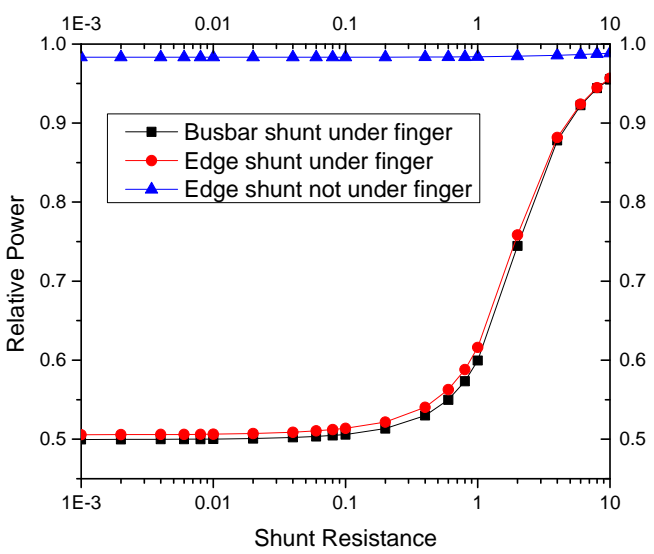

Figure 5. Variation of relative power with shunt resistance for different spatial positions of shunts.

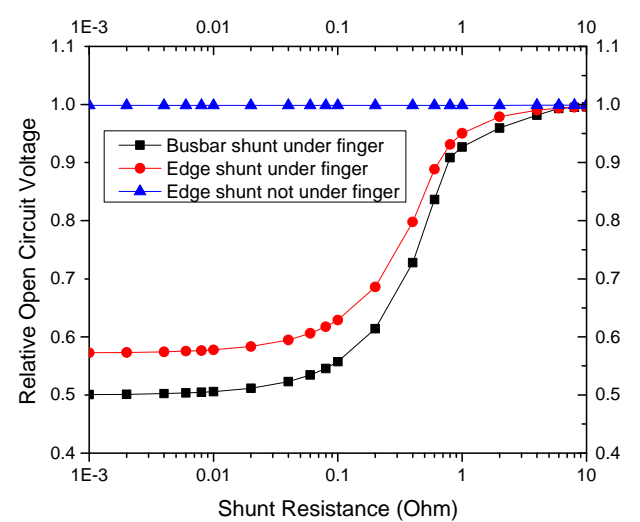

Figure 6. Variation of relative open circuit voltage with shunt resistance for different spatial positions of shunts.

Figure 7 illustrates the variation of relative power of the PV module for three local positions of shunts considered in the present work. Figure 8 visualizes the variation of relative open circuit voltage for three spatial locations of shunts considered in the present work.

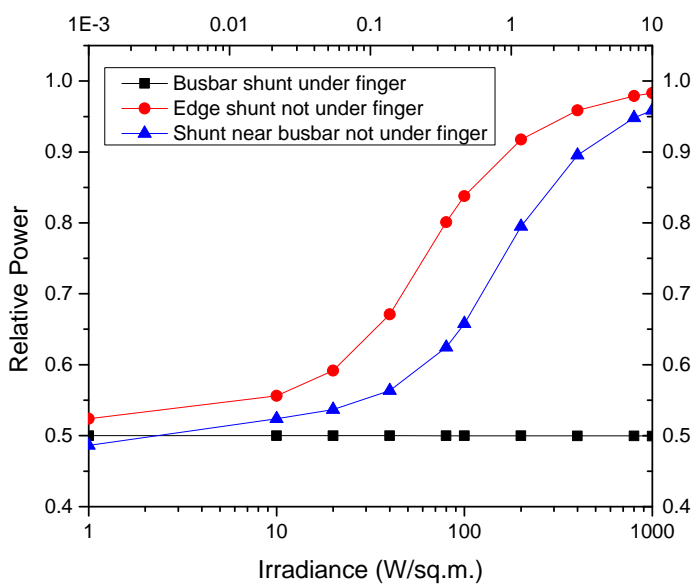

Figure 7. Variation of relative power with irradiance for different spatial positions of shunts. 


\subsection{Influence of Proximity to Metallization}

Influence of proximity to metallization has been investigated for a common type of shunt: the edge shunt. Figure 9 presents the variation of relative power of the PV module with shunt resistance for the edge shunt under and not under finger metallization. Figure 10 presents the variation of relative open circuit voltage for the same case of shunting.

Figure 11 illustrates the variation of relative power with the number of shunted cells connected in the module for the edge shunt under and not under finger metallization, whereas the Fig. 12 presents the variation of relative open circuit voltage for the same case of shunting.

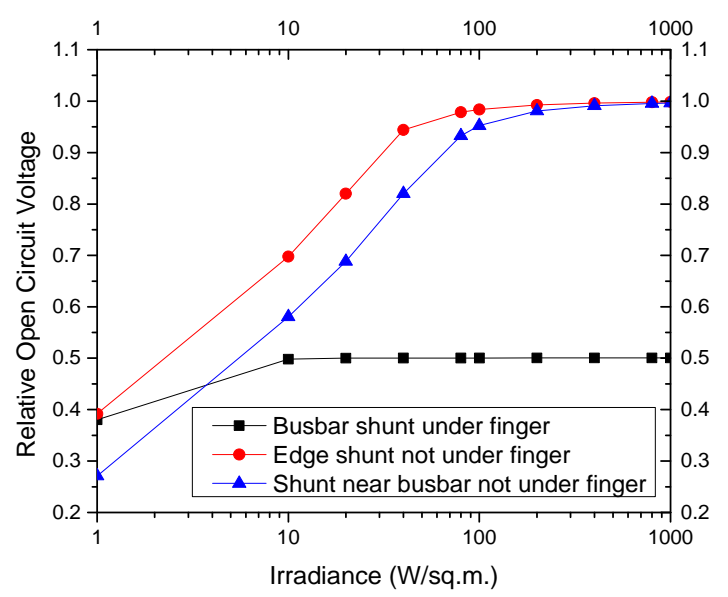

Figure 8. Variation of relative open circuit voltage with irradiance for different spatial positions of shunts.

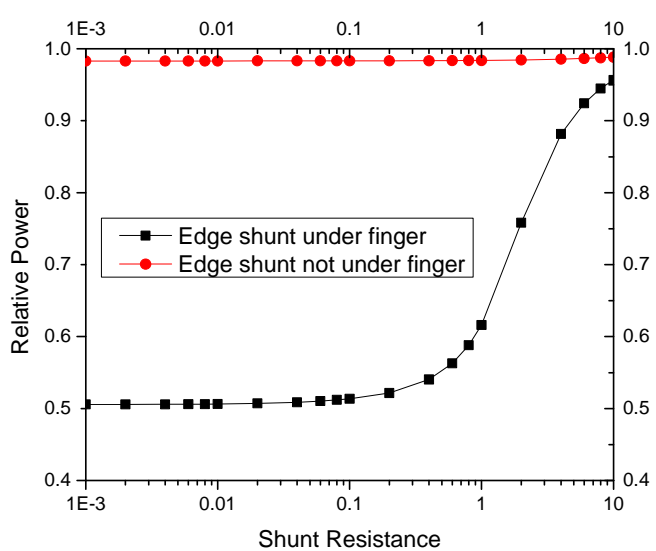

Figure 9. Variation of relative power with shunt resistance for shunt under and not under finger metallization.

\subsection{Influence of Number of Shunted Cells}

Influence of the number of shunted cells has been studied by keeping the shunt resistance and shunt area same for each shunted cell connected in the module. Figure 13 presents, the variation of relative power with number of shunted cells connected in the PV module for three cases of shunting considered in the present work. Figure 14 illustrates the variation of relative open circuit voltage with number of shunted cells for the three spatial positons of shunting. The trend reveals that, the spatial variation is more accentuated, in the case of relative open circuit voltage when compared to the relative power.

\subsection{Influence of Area of the Shunt}

The effect of area the shunt has been studied by keeping the absolute shunt resistance same in all the cases of shunting considered, while varying the shunt area and the area normalized shunt resistance. 
Figure 15 illustrates the variation of relative power of the PV module with varying irradiances for two different shunt areas, however having the same absolute shunt resistance. Figure 16 summarizes the variation of relative open circuit voltage of the PV module with varying irradiances for two different shunt areas considered in the present work.

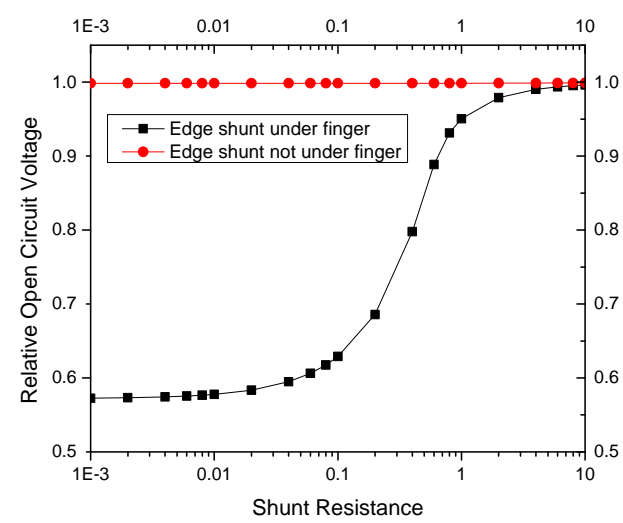

Figure 10. Variation of relative open circuit voltage with shunt resistance for shunt under and not under finger metallization.

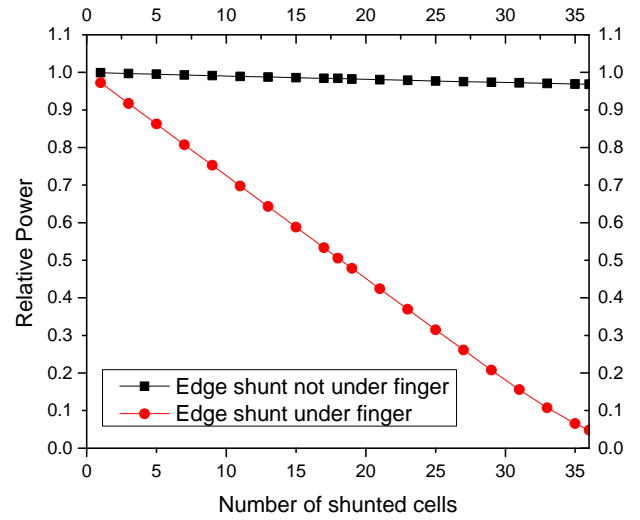

Figure 11. Variation of relative power with number of shunted cells for shunt under and not under finger metallization.

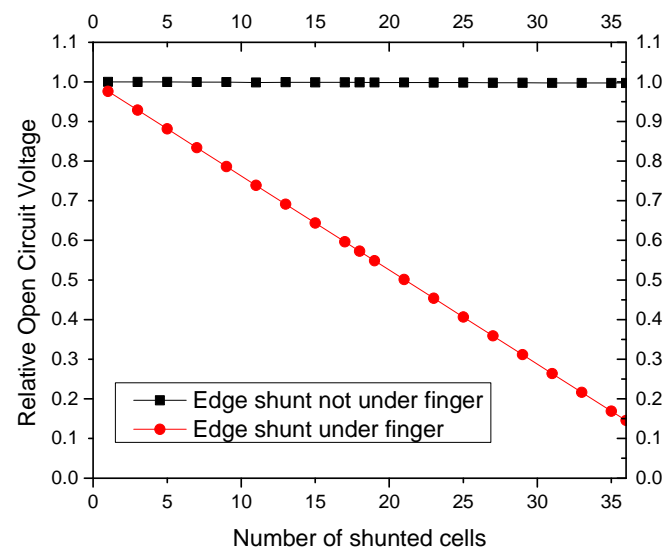

Figure 12. Variation of relative open circuit voltage with number of shunted cells for shunt under and not under finger metallization. 


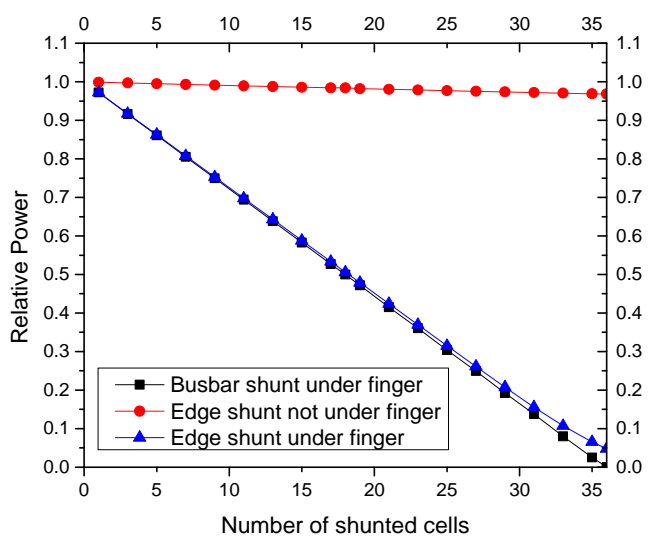

Figure 13. Variation of relative power with number of shunted cells for different spatial positions of shunts.

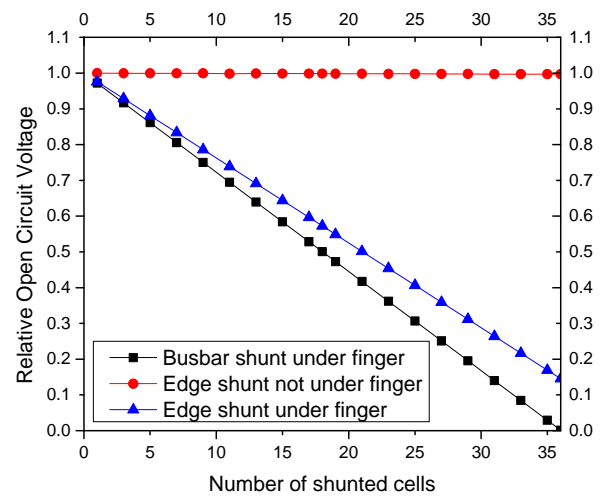

Figure 14. Variation of relative open circuit voltage with number of shunted cells for different spatial positions of shunts.

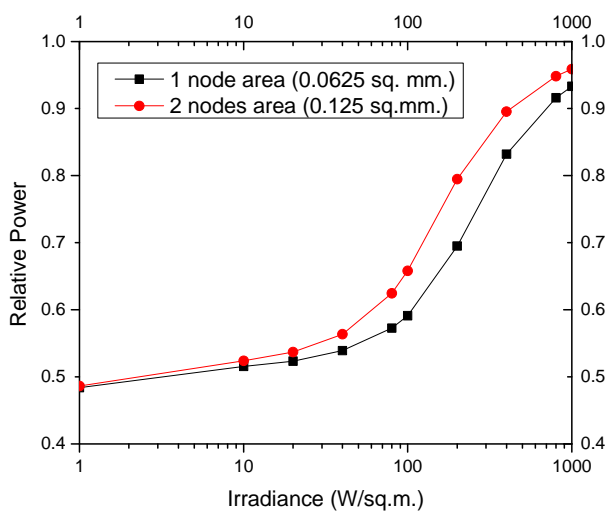

Figure 15. Variation of relative power with irradiance for two different shunt areas and having the same absolute shunt resistance. 


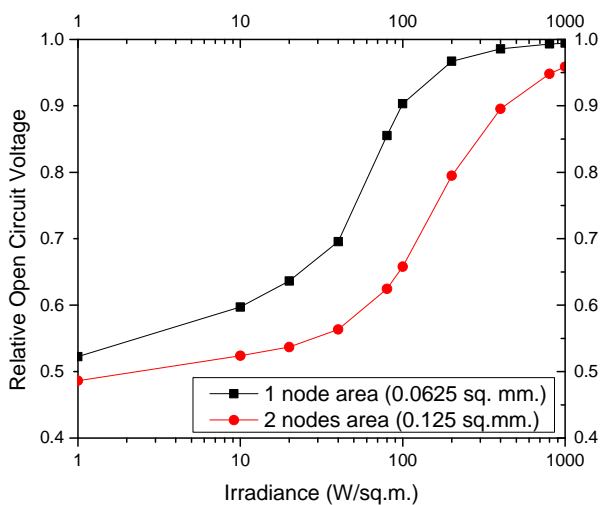

Figure 16. Variation of relative open circuit voltage with irradiance for two different shunt areas and having the same absolute shunt resistance.

\section{Discussion}

\subsection{Influence of Shunt Magnitude}

Figure 5 reveals that at very low shunt values the relative power can degrade to about $50 \%$ for all the shunt positions under finger or busbar metallization. At high shunt values close to $10 \Omega$, the relative power improves to $95 \%$, for the shunt positions under metallization. For the shunts under metallization, in the intermediate region, the relative power increases in an almost exponential manner with the increase in shunt resistance. However, for edge shunt not under finger, the reduction in relative power is only $2 \%$, and remains almost independent of the variation in shunt resistance value.

At very low values of shunt, the PV cell's electrical characteristics is critically influenced by the shunt and thus the output power will be degraded drastically, however the variation in the relative power generated between various local shunt positions still holds importance. When the values of shunt resistance are very high, the PV cell is generating almost its full output power and in this region; difference due to local spatial position vanishes. It is evident from the study that, when the shunts are not under finger or busbar metallization, there can be considerable improvement in the electrical performance of the PV module.

For a higher shunt resistance, i.e., for the value of $10 \Omega$, the relative open circuit voltage reaches almost $100 \%$ whereas the relative power for the same value of shunt resistance has reached only $95 \%$ under the same irradiance. However, the spatial variation becomes more obvious and a maximum difference of $50 \%$ between two different shunt positions has been revealed by Fig. 6 . For the case of edge shunt not under finger, relative open circuit voltage remains more or less unaffected by the shunt resistance magnitude, as seen in the case of relative power.

\subsection{Influence of Irradiance}

From the simulation results obtained in Fig. 7, it is apparent that the spatial position of shunts in PV modules is very much important when considering the shunt related losses, particularly at low irradiance levels. Figure 7 reveals that there can be a difference of more than $45 \%$ between different positions of shunts located not under metallization for the values of shunt resistance considered in the present work. This is obviously a significant difference, since an increase in output power in this range can be of considerable importance. Further since, the actual shunt value may approach the range of $0.001 \Omega$ in some cases, the impact of shunt may be accentuated to critical levels, resulting in degradation in relative power of even $50 \%$.

From the simulation results, it has been observed that there can be a variation in relative open circuit voltage from $15 \%$ and up to a maximum of even $50 \%$ between different spatial locations of shunts for the same shunt resistance and shunt area, thus revealing the critical importance of shunt positions. At the lowest value of the shunt resistance considered, the loss in relative open circuit voltage can vary 
from $60 \%$ to more than $70 \%$. Figure 7 and 8 also reveal that at high irradiance levels near to 1 Sun $\left(1000 \mathrm{~W} / \mathrm{m}^{2}\right)$, the difference in shunt losses gradually reduces to a minimum, for shunts not under metallization since the impact of shunt would decrease in comparison to the low irradiance case. However, for the busbar shunt under finger, i.e. a shunt under metallization, the trend in both Fig. 7 and Fig. 8 reveals that the relative power and relative open circuit voltage remains relatively independent of the variation in irradiance levels. This surprising result can be correlated to the fact that, the presence of metallization busbar and fingers under the shunt holds critical significance on the influence of shunt and the sinking of current by the shunt.

Impact of the shunt on the PV module's electrical performance diminishes comparatively, at higher levels of incident solar radiation, since there would be more lateral current flow and it is expected that there would be reduction in degradation due to shunting. For the shunt positions not under metallization, it has been evident in the present study that, the PV module has a slightly improved performance at higher irradiances. However, for the shunts under metallization, i.e. say, busbar shunt under finger, the PV module's electrical performance depends critically on the shunt resistance and the influence of irradiance diminishes considerably.

\subsection{Influence of Proximity to Metallization}

The results reveal the significant effect of metallization at the lowest shunt values in the cases of both the relative power and the relative open circuit voltage. The presence of finger metallization under the shunt alone has led to a maximum difference of around $50 \%$ in relative power, whereas in the case of relative open circuit voltage the difference between the two shunts has been found to be around $45 \%$ for critically low values of shunt resistance. In the context of above findings, the influence of proximity of the shunt to the metallization assumes a critical importance. The results obtained lead to the inference that even the shunts located at the edge or even corner of the PV cell can critically degrade the performance of the PV module when they are located under finger metallization.

Further, it is revealed by Fig. 9 and Fig. 10 that shunts of even very low resistances could become almost harmless when they are positioned at certain spatial locations such as at the edge or corner of the PV cell, which are not under metallization. When the shunts are located away from the finger and busbar metallization, they will be screened by the surrounding sheet resistance and the effect of the shunt decreases. The greater the sheet resistance, the greater will be the effect due to shunt screening by the sheet resistance. The explanation for the impact of metallization can be related to the fact that the busbars and fingers carry far greater current, being the most conductive path for the current in the PV module. Hence when a shunt occurs in the close proximity of busbar or fingers as well as under the busbars or fingers, the probability of greater current sinking through the shunt increases.

The dramatic influence of the proximity of metallization is revealed by both Fig. 11 and Fig.12. The maximum difference in relative power can be even $90 \%$ whereas the maximum difference in relative open circuit voltage can be even $80 \%$ between the two spatial locations of shunts, due to the proximity of the shunt to finger metallization.

\subsection{Influence of Number of Shunted Cells}

Figure 13 reveals that even if many numbers of cells are shunted in a module, the impact on the module performance is drastically influenced by the spatial position of the shunt. The trend in Figure 14 reveals that, the spatial variation is more accentuated, in the case of relative open circuit voltage when compared to the relative power. For the most critical spatial position of shunt considered, i.e. the busbar shunt under finger, both the relative power and relative open circuit voltage reduce to very low values resulting in severe loss in performance of the photovoltaic module.

\subsection{Influence of Area of the Shunt}

Figure 15 shows that, an increase in area of the shunt for the same value of absolute shunt resistance, will cause more loss in relative power of the PV module. The main reason for the aforementioned effect can be attributed to the fact that an increase in the area of the shunt would bring the edge of the shunt area near to more number of metallization fingers or busbar compared to a smaller shunt area. A second 
reason is that most of the current in the shunt tend to flow along the edges of the area and not through the center [27]. Due to the above mentioned effects, a greater perimeter results in a larger area of influence of the shunt. In the case of relative open circuit voltage also, as revealed by Fig.16, the greater shunt area results in increased loss in relative open circuit voltage of the PV module.

\section{Conclusions}

A systematic investigation on the electrical mismatch losses due to the presence of shunts at different locations on the electrical performance of PV modules, has been carried out by utilizing the distributed diode model. The investigation has produced very interesting results, on the performance loss caused by the localized shunts positioned at different significant locations in the PV module and presented a novel approach to evaluate the actual power loss as well as loss in open circuit voltage caused by the shunts.

The shunt resistance, irradiance, location of shunt, number of shunted cells and area of the shunt have been systematically varied and impact on the photovoltaic module performance has been determined. The effect of shunt on the module's electrical performance has been investigated in terms of relative power and relative open circuit voltage. Important finding is that, the electrical performance of the PV module with shunts in it, depends critically on the shunt position and proximity to the metallization to the extent that the difference in loss in the relative power can be even $90 \%$ between different shunt positions and the difference in loss in the relative open circuit voltage can be even $80 \%$. Comparing with shunts under metallization, there is an improvement of $80 \%$ to $90 \%$ in relative power for the most of the shunts not under metallization, for the lowest values of shunt resistance considered in the present work. In general, it was found that the proximity to the busbar and finger metallization and the shunt position holds the key to the impact the shunt will have on the photovoltaic module performance in addition to the resistance of shunt itself. An impressive gain in the photovoltaic module's electrical performance can be achieved by either avoiding the occurrence of shunts at the found significant positions or isolating them at the cell production stage by laser or chemical method or removing them.

\section{References}

1. M. Barbato, M. Meneghini, A. Cester, G. Mura, E. Zanoni, and G. Meneghesso, "Influence of shunt resistance on the performance of an illuminated string of solar cells: theory, simulation, and experimental analysis", IEEE Trans. Device and Materials Reliability, vol. 14(4), pp. 942-950, 2014.

2. Y.P. Botchak Mouafi, A.S. Zuschlag, P.-Y. Pichon, J.M. Fritz, A. Schonecker, and G. Hahn, "Novel RGS materials with high fill factors and no material-induced shunts with record solar cell efficiencies exceeding 16\%", Solar Energy Materials \& Solar Cells, vol.146, pp. 25-34, 2016.

3. D. Chithambaranadhan, V. Veeramuthu, Q. Nguyen, T. C. Lommasson, R. Goldberg, and T. Boström, "Efficiency improvement in nonprime crystalline Silicon solar cells by chemical isolation of shunts under front metallization", IEEE J. Photovoltaics, vol. 5(1), pp. 206-211, 2015.

4. A. Compagnin, M. Meneghini, M. Barbato, V. Gilberto, A. Cester, M. Vanzi, G. Mura, E. Zanoni, and G. Meneghesso, "Thermal and electrical investigation of the reverse bias degradation of silicon solar cells", Microelectronics Reliability, vol. 53, pp. 1809-1813, 2013.

5. S. Dongaonkar, S. Loser, E.J. Sheets, K. Zaunbrecher, R. Agrawal, T.J. Marks , and M.A. Alam, "Universal statistics of parasitic shunt formation in solar cells, and its implications for cell to module efficiency gap", Energy Environ. Sci., vol. 6, pp. 782-787, 2013.

6. M. Fortes, E. Comesana, J. A. Rodriguez, P. Otero, and A.J. Garcia-Loureiro, "Impact of series and shunt resistances in amorphous silicon thin film solar cells", Sol. Energy, vol. 100, pp.114-123, 2014.

7. D. Giaffreda, P. Magnone, M. Meneghini, M. Barbato, G. Meneghesso, E. Zanoni, E. Sangiorgi, and C. Fiegna, "Local shunting in multicrystalline Silicon solar cells: distributed electrical simulations and experiments", IEEE J. Photovoltaics, vol. 4(1), pp. 40- 47, 2014.

8. H. Guthrey, S. Johnston, D.N. Weiss, S. Grover, K. Jones, A. Blosse, and M. Al-Jassim, "Three- dimensional minority- carrier collection channels at shunt locations in silicon solar cells", Sol. Energy, vol. 135, pp. 163-168, 2016 . 
9. A.B. Phillips, R.R. Khanal, Z. Song, S.C. Watthage, K.R. Kormanyos, and M.J. Heben , "Simultaneous shunt protection and back contact formation for CdTe solar cells with single wall carbon nanotube layers", Applied Physics Letters, vol.107, pp. 253901 (1-4), doi:10.1063/1.4938130, 2015.

10. A. Johansson, R. Gottschalg, and D.G. Infield, "Modelling shading on amorphous silicon single and double junction modules", 3rd World Conference on photovoltaic energy conversion, vol.2, pp. 1934-1937, 2003.

11. A. Woyte, J. Nijs, and R. Belmans, "Partial shadowing of photovoltaic arrays with different system configurations: literature review and field test results", Sol. Energy, vol. 74, pp. 217- 233, 2003.

12. A. Hovestad , P.M.M.C. Bressers , R.M. Meertens , C.H. Frijters, and W.P. Voorthuijzen, "Electrochemical etching of molybdenum for shunt removal in thin film solar cells", J. Appl. Electrochem. vol.45, pp.745-753, 2015.

13. L. Zhang, H. Shen, Z. Yang, and J. Jin, "Shunt removal and patching for crystalline silicon solar cells using infrared imaging and laser cutting". Prog. Photovoltaics Res. Appl., vol.18(1), pp. 54-60, 2010.

14. M.D. Abbott, T. Trupke, H.P. Hartmann, R. Gupta, and O. Breitenstein, "Laser isolation of shunted regions in industrial solar cells", Prog. Photovoltaics Res. Appl. vol.15, pp. 613-620, 2007.

15. H.L Hao, S.H. Zhong, X. Zhang, and W.Z. Shen, "Optimization of shunt isolation processing for silicon solar cells via laser and chemical etching", Applied Surface Science, vol. 311, pp. 870 - 875, 2014.

16. S.E. Foss, B.R. Olaisen, E.S. Marstein, and A. Holt, "A new 2.5D distributed SPICE model of solar cells ", In: Proceedings of 21st European Photovoltaic Solar Energy Conference and Exhibition, pp. 430-434, 2006.

17. B. Galiana, C. Algora, I. Rey-Stolle, and I. G. Vara, "A 3-D Model for concentrator solar cells based on distributed diode units", IEEE Trans. Electronic Dev., vol. 52(12), pp. 2552- 2558, 2005.

18. R. Gupta , O. Breitenstein , J. Zettner, and D. Karg, "In-line shunt detection in solar cells by fast lock-in infrared thermography", In: Proceedings of 22nd European Photovoltaic Solar Energy Conference and Exhibition. pp. 1975-1978, 2007.

19. R. Gupta, P. Somasundaran, and D. K. Nandi, "Electrical simulation and characterization of shunts in solar cells", J. Appl. Mechanics Mater., vol. 110-116, pp. 2453- 2457, 2012.

20. P. Somasundaran, A. Sinha, and R. Gupta, "Simulation and characterization of spatial variation of shunts in industrial solar cells by PSpice and dark lock-in infrared thermography", In: Proceedings of 27th European Photovoltaic Solar Energy Conference, pp. 744-748, 2012.

21. P. Somasundaran and R. Gupta, "Influence of local shunting on the electrical performance in industrial Silicon solar cells", Sol. Energy, vol. 139, pp. 581-590, 2016.

22. A. Zekry and A.Y. Al-Mazroo, "A distributed SPICE-model of a solar cell", IEEE Trans. Electronic Dev. vol. 43(5), pp. 691-700, 1996.

23. P. Somasundaran and R. Gupta, "Evaluation of shunt losses in industrial Silicon solar cells", International Journal of Photoenergy, vol. 2016, 2016, http://dx.doi.org/10.1155/2016/8029608.

24. OrCAD PSPICE release 16.3. Cadence Design System Inc. (2011)

25. P. Somasundaran, M. Shilpi and R. Gupta, "Evaluation of mismatch losses due to shunts in industrial Silicon photovoltaic modules", In: Proceedings of th $^{\text {th }}$ International Conference on Environment and Industrial Innovation, 2017, doi:10.1088/1755-1315/67/1/012013.

26. J. Salinger, "Measurement of solar cell parameters with dark forward I-V characteristics," Acta Polytechnica, vol. 46, pp. 25-27, 2006.

27. F. W. Fecher, A. P. Romero, C. J. Brabec and C. Buerhop-Lutz, "Influence of shunt on the electrical behavior in thin film photovoltaic modules - A 2 D finite element simulation study ", Sol. Energy, vol. 105, pp. 494- 504, 2014. 